study and the development of the abstract., Maura Couto: None declared, Nimmisha Govind: None declared, Arvind Chopra Grant/research support from: Pfizer Inc, Karen Solomon-Escoto: None declared, Elizabeth Murphy Consultant for: Has received support from Roche to audit work on behalf of the Scottish Society for Rheumatology., Thomas Huizinga Consultant for: Merck, UCB, Bristol Myers Squibb, Biotest AG, Pfizer, GSK, Novartis, Roche, Sanofi-Aventis, Abbott, Crescendo Bioscience Inc., Nycomed, Boeringher, Takeda, Zydus, Epirus, Eli Lilly, Cornelia Allaart: None declared

DOI: 10.1136/annrheumdis-2019-eular.3927

\section{SAT0078 MAJOR CHANGES IN THERAPY PRODUCE SIGNIFICANT CLINICAL IMPROVEMENT ACROSS A BROAD RANGE OF CLINICAL DISEASE ACTIVITY IN US VETERANS WITH RHEUMATOID ARTHRITIS}

Grant Cannon ${ }^{1}$, Wei Chen ${ }^{1}$, Jincheng Shen ${ }^{2}$, Neil Accortt ${ }^{3}$, David Collier ${ }^{3}$, Brian Sauer'. 'Salt Lake City VA Medical Center and University of Utah, Salt Lake City, United States of America; ${ }^{2}$ University of Utah, Biostatistics, Salt Lake City, United States of America; ${ }^{3}$ Amgen Inc., Thousand Oaks, United States of America

Background: Our recent work showed that $41 \%$ of patients with moderate/severe rheumatoid arthritis (RA) by Disease Activity Score for 28 joint count (DAS28) did not have changes in RA therapy as recommended by current guidelines (1). Reasons identified for the decision not to escalate therapy was provider's opinion that RA disease was adequately controlled despite moderate/severe disease activity by DAS28, and that changes in therapy may not produce significant improvements in disease activity (1). Objectives: 1) Compare short-term differences in ACR20 response between patients with and without a major therapeutic change (MTC) over a range of disease activity; 2) Determine whether ACR20 responses vary by disease activity measures (DAMs) used to assess disease activity (i.e., DAS28, Clinical Disease Activity Index [CDAI], Routine Assessment of Patient Index Data 3 [RAPID3]).

Methods: Each clinic visit for US Veterans enrolled in the VA Rheumatoid Arthritis (VARA) registry was evaluated if the visit had: 1) a complete set of DAMs (DAS28, CDAI, RAPID3) recorded; 2) two other visits with all DAMs during the preceding 18 months separated by at least 60 days and one visit with all DAMs between 60 and 180 days following the visit date; 3) clinical data available for 18 months prior to visit date; and 4) $\geq 6$ tender and $\geq 6$ swollen joints at visit date. Each patient was assessed for MTC within 1 week before and 30 days after visit date. MTC was defined as any of the following: 1) initiation of new biologic or nonbiologic disease-modifying antirheumatic drug (DMARD) or prednisone (as new agent or after 90-day gap during baseline); 2) escalation of DMARD dose by $\geq 25 \%$; or 3 ) increase in monthly average prednisone dose by $25 \%$; and/or 4 ) injection of 2 or more joints with corticosteroids. Clinical improvement was defined as an ACR20 response comparing each eligible visit DAM to the first follow-up visit DAM observed between 60 and 180 days of the eligible visit date. ACR20 response was compared between eligible visits with and without a MTC and stratified by quartiles of disease activity by each DAM. The Generalized Estimating Equations (GEE) model was fitted using the exchangeable working covariance structure to account for clustering of visits within patients. Models for each DAM were adjusted for age, disease duration, race, seropositive status, comorbidities, disease stability, and recent medication changes in the observations period prior to the visit date.

Results: There were 383 patients $(92 \%$ were male, mean age was 62.9 years, mean disease duration was 12.5 years, $83 \%$ tested positive for rheumatoid factor, and $79 \%$ positive for anti-cyclic citrullinated peptide antibodies) who contributed 1,193 eligible visits. Visits with a MTC had a higher rate of ACR20 response in comparison to visits without a MTC at all levels of disease activity. A MTC at a visit with the highest disease activity (quartile 4) consistently had the largest proportion of follow-up visits with an ACR20 response. The overall effect for MTC was statistically significant across all 3 DAMs. Across quartiles, the MTC group consistently had a higher proportion of follow-up visits with ACR20 response compared to the group without a MTC. Risk Ratios from the adjusted analysis are presented in the table.

Conclusion: All patients with active RA have a significant potential to benefit with a MTC. This potential for improvement was seen across all degrees of disease activity and with all three DAMs.

\begin{tabular}{|c|c|c|c|}
\hline \multicolumn{4}{|c|}{ ACR 20 response with or without major therap eutic change (MTC) } \\
\hline DAMs, quartiles (Q) & With MTC & Without MTC & Risk Ratio \\
\hline \multicolumn{4}{|l|}{ DAS28 } \\
\hline Overall effect & $34 \%(29 \%, 39 \%)$ & $22 \%(18 \%, 28 \%)$ & $1.52(1.23,1.88)$ \\
\hline Q1:2.35-4.87 & $25 \%(17 \%, 33 \%)$ & $15 \%(10 \%, 22 \%)$ & $1.60(0.98,2.54)$ \\
\hline Q2: $4.88-5.60$ & $33 \%(24 \%, 43 \%)$ & $20 \%(14 \%, 28 \%)$ & $1.65(1.07,2.56)$ \\
\hline Q3:5.61-6.29 & $30 \%(23 \%, 39 \%)$ & $23 \%(16 \%, 30 \%)$ & $1.31(0.89,1.95)$ \\
\hline Q4:6.30-8.76 & $47 \%(40 \%, 57 \%)$ & $30 \%(22 \%, 41 \%)$ & $1.55(1.12,2.38)$ \\
\hline \multicolumn{4}{|l|}{ CDAI } \\
\hline Overall effect & $35 \%(31 \%, 40 \%)$ & $23 \%(19 \% .31 \%)$ & $1.52(1.19,1.89)$ \\
\hline Q1: $14.7-26.6$ & $31 \%(22 \%, 41 \%)$ & $15 \%(10 \%, 21 \%)$ & $2.10(1.28,3.35)$ \\
\hline Q2: $26.7-32.9$ & $27 \%(20 \%, 35 \%)$ & $21 \%(15 \%, 31 \%)$ & $1.25(0.84,1.95)$ \\
\hline Q3: $33.0-41.7$ & $41 \%(33 \%, 49 \%)$ & $30 \%(23 \%, 39 \%)$ & $1.34(1.02,1.87)$ \\
\hline Q4: $41.9-71.0$ & $42 \%(34 \%, 52 \%)$ & $26 \%(18 \%, 39 \%)$ & $1.60(1.10,2.52)$ \\
\hline \multicolumn{4}{|l|}{ RAPID3 } \\
\hline Overall effect & $34 \%(29 \%, 38 \%)$ & $21 \%(17 \%, 26 \%)$ & $1.59(1.28,2.00)$ \\
\hline Q1: $0.33-3.61$ & $22 \%(14 \%, 31 \%)$ & $18 \%(12 \%, 25 \%)$ & $1.23(0.69,1.91)$ \\
\hline $32-4.99$ & $39 \%(31 \%, 49 \%)$ & $21 \%(15 \%, 28 \%)$ & $1.86(1.32,2.70)$ \\
\hline Q3: $5.00-6.28$ & $31 \%(23 \%, 39 \%)$ & $20 \%(13 \%, 29 \%)$ & $1.53(0.92,2.46)$ \\
\hline Q4: $6.31-9.55$ & $42 \%(35 \%, 51 \%)$ & $25 \%(17 \%, 34 \%)$ & $1.68(1.19,2.62)$ \\
\hline
\end{tabular}

\section{REFERENCE}

[1] Stever, et al. Utility of administrative and clinical data to predict major change in medical treatment in US Veterans enrolled in the Veterans Affairs Rheumatoid Arthritis (VARA) registry. Clin Exp Rheumatol; 2018 Epub ahead of print.

Disclosure of Interests: Grant Cannon Grant/research support from: Amgen Inc., Wei Chen Grant/research support from: Amgen Inc., Jincheng Shen: None declared, Neil Accortt Shareholder of: Amgen Inc., Employee of: Amgen Inc., David Collier Shareholder of: Amgen Inc. Employee of: Amgen Inc., Brian Sauer Grant/research support from: Amgen Inc.

DOI: 10.1136/annrheumdis-2019-eular.336

\section{SAT0079 PREDICTING PATIENTS WITH HIGH PAIN \& PSYCHOLOGICAL SYMPTOMS (P\&PS) IN EARLY RHEUMATOID ARTHRITIS USING LATENT CLASS ANALYSIS. RESULTS FROM THE TACERA, A LONGITUDINAL COHORT}

Lewis Carpenter, Katie Bechman, Andrew Cope, Elena Nikiphorou, James Galloway, Sam Norton, On behalf of all the researchers of the Towards A Cure for Early Rheumatoid Arthritis (TACERA) working group. King's College London, London, United Kingdom

Background: Despite advances in the treatment of rheumatoid arthritis (RA), pain and psychological symptoms remain a burden for many patients. The precise relationship between inflammation and patient reported symptoms, such as pain, fatigue and mental health in the disease is unclear. However, evidence suggests that over time there may be discordance between inflammation and patient reported outcomes, such that some patients with low inflammation will experience persistent symptoms. It is hypothesised that three distinct patient sub-groups exist; low inflammation/low symptoms, low inflammation/high symptoms, and high inflammation/high symptoms.

Objectives: To identify sub-groups of patients with respect to inflammatory markers and levels of P\&PS over time.

Methods: Demographic, clinical and laboratory data were recorded at baseline (pre-treatment), 6, 12, and 18-months from 239 early RA patients recruited to the Towards A Cure for Early Rheumatoid Arthritis (TACERA) cohort. Individual components of the DAS28 (tender joints, swollen joints, ESR, CRP and patient global) at post-treatment assessments, along with patient reported visual analogue scales for pain, fatigue and the SF-36 Mental Component Score (MCS) were used to identify sub-groups using longitudinal latent class analysis (LCA). Logistic regression models identified variables associated with class membership at 6 , 12 and 18-months follow-up.

Results: LCA indicated two rather than the hypothesised three subgroups; low inflammation/low symptoms and low inflammation/high symptoms. This was likely because ESR and CRP were well controlled by 6 months and maintained by 18-months for the majority of individuals. There were $86(36 \%) 59(35 \%)$ and 41 (39\%) classified as having high symptoms at 6,12 and 18 -months. $78 \%$ of patients initially in the low symptom group remained in the low symptom group between 6 and 18- 
months. Rheumatoid Factor (RF) positivity and higher baseline fatigue were associated with high symptoms at 6months; decreasing ESR from 6 to 12-months was associated high symptoms at 12months, and having high symptoms at 12-months, along with reduced Swollen Joint Count (SJC), CRP and MCS from month 12 to 18 was associated with high symptoms at 18 -months.

Conclusion: Tight treatment control resulted in controlled Inflammation by 6-months, resulting in just two main patient sub-groups; those with low and high P\&PS. Over one-third of patients experienced high pain and psychological symptoms. Membership of the high symptom group was associated with RF positivity but was mainly driven by prior symptom experience. Whilst inflammatory control remains a primary target, other treatments targeting pain, fatigue and mental health must be considered to reduce the burden of disease.

Disclosure of Interests: Lewis Carpenter: None declared, Katie Bechman: None declared, Andrew Cope: None declared, Elena Nikiphorou: None declared, James Galloway Consultant for: Pfizer Inc, Sam Norton: None declared

DOI: 10.1136/annrheumdis-2019-eular.7727

\section{SAT0080 COMPARISON OF INFLAMMATORY CYTOKINES LEVELS IN RHEUMATOID ARTHRITIS WITH CAROTID PLAQUE; CASE-CONTROL STUDY}

Karla Paola Cuéllar-Calderón ${ }^{1}$, Dionicio Ángel Galarza-Delgado ${ }^{1}$, José Ramón Azpiri-López ${ }^{2}$, Iris Jazmin Colunga-Pedraza ${ }^{2}$, Ileana Cecilia ReynosaSilva $^{1}$, Marielva Castro-González ${ }^{1}$, Carolina Marlene Martínez-Flores ${ }^{2}$, Raymundo Pineda', Gisela García-Arellano ${ }^{1}$, Rosa Arivizú Rivera ${ }^{1} .{ }^{1}$ Hospital Universitario Dr José Eleuterio Gonzalez, Rheumatology, Monterrey, Mexico;

${ }^{2}$ Hospital Universitario Dr José Eleuterio Gonzalez, Cardiology, Monterrey, Mexico

Background: There is a $50 \%$ increase in cardiovascular mortality in RA compared to controls. Chronic inflammation causes endothelial dysfunction and accelerated atherosclerosis. Key molecular pathways in this process are dependent on cytokines like TNF- $\alpha$, IL-1, IL-6, among others, which are shared with RA. Increased disease activity could contribute to atherosclerosis. Carotid ultrasound (US) has recently been recommended as a screening tool for early detection of subclinical atherosclerosis.

Objectives: To compare different cytokines between Mexican-mestizo RAsubjects with/without carotid plaque (CP).

Methods: An observational cross-sectional trial was designed. Inclusion criteria: age between 40-75 years old, fulfillment of the 2010 ACR/EULAR classification criteria, and detection of a CP during a carotid US. Subjects with a prior diagnosis of cardiovascular disease or a poor US window were excluded. RA subjects were matched to controls (RA patients without $\mathrm{CP}$ ) by age and cardiovascular (CV) comorbidities. Every subject had a carotid US performed; reviewed by two board-certified radiologists. Cytokines measured were IL-1, IL-6, TNF- $\alpha$, VCAM-1, ICAM-1 and MMP9, using an ELISA reader (Glomax E9032). Descriptive analysis was done with frequencies (\%), median (q25-q75), and comparisons between groups with Chi square test and Mann U Whitney's test.

Results: 71 subjects were included, 95.8\% were females, with a median age of 58 years (54-65). Levels of cytokines in Table 1. Comparisons between groups are in Table 2. Groups were well balanced, with no differences in CV comorbidities $(p>0.05)$. No significant differences among cytokine levels regarding CP were found. Subjects in remission $(n=12$, $33 \%)$ had a lower prevalence of CP ( $p<0.05$, OR: $0.3 ; 95 \% \mathrm{Cl}: 0.1-0.9)$ and a lower median IL-1 level than those with higher disease activity $(p<0.05)$. No significant differences were found among any other of the compared cytokines.

Table 1. Cytokines levels

\begin{tabular}{lc}
\hline & Median(q25-q75) \\
\hline IL1, pg/ml & $8.1(6.6-9.6)$ \\
TNF-a, pg/ml & $76(61-101)$ \\
IL6, pg/ml & $4.4(4.1-4.8)$ \\
ICAM, ng/ml & $91(61-141)$ \\
VCAM, ng/ml & $56.5(41.3-65.1)$ \\
MMP9, pg/ml & $811(721-931)$ \\
\hline
\end{tabular}

Table 2. Clinical characteristics.

\begin{tabular}{|c|c|c|c|}
\hline Variable & $\begin{array}{c}\text { CP } \\
(n=37)\end{array}$ & $\begin{array}{l}\text { No } C P \\
(n=34)\end{array}$ & $p$ \\
\hline Age, years median (q25-q75) & $\begin{array}{l}59.2(54.8- \\
66.1)\end{array}$ & $57.7(53-61.2)$ & NS \\
\hline Female, n (\%) & $35(94.6)$ & $33(97.1)$ & NS \\
\hline Dyslipidemia, n (\%) & 7 (18.9) & $6(17.6)$ & NS \\
\hline T2DM, n (\%) & $10(27)$ & $7(20.6)$ & NS \\
\hline Hypertension, n (\%) & $12(32.4)$ & $10(29.4)$ & NS \\
\hline BMI, median (q25-q75) & $29(26.5-31.1)$ & $\begin{array}{l}27.9(24.6- \\
33.2)\end{array}$ & NS \\
\hline Disease duration, media \pm SD & $12.4 \pm 9.9$ & $10.6 \pm 9$ & NS \\
\hline DAS28 CRP, median (q25-q75) & $2.9(1.5-3.9)$ & $2.39(1.8-3.1)$ & NS \\
\hline MTX n, (\%) & $17(45.9)$ & $22(64.7)$ & NS \\
\hline Prednisone, n (\%) & $27(73)$ & $24(70.6)$ & NS \\
\hline IL-1 pg/ml, median (q25-q75) & $8.7(6.7-10.1)$ & $7.9(6.1-9.3)$ & NS \\
\hline TNF-a pg/ml, median (q25-q75) & $76(61-101)$ & $76(61-96)$ & NS \\
\hline IL-6 pg/ml, median (q25-q75) & $4.4(4.1-4.9)$ & $4.4(3.9-4.8)$ & NS \\
\hline ICAM ng/ml, median (q25-q75) & $91(61-118.5)$ & $83.5(61-217.2)$ & NS \\
\hline VCAM ng/ml, median (q25-q75) & $\begin{array}{c}58.1(42.1- \\
64.8)\end{array}$ & $\begin{array}{c}54.3(35.1- \\
65.9)\end{array}$ & NS \\
\hline MMP9 pg/ml, median (q25-q75) & $\begin{array}{c}811(711- \\
938.5)\end{array}$ & $\begin{array}{c}821(724.7- \\
931)\end{array}$ & NS \\
\hline $\begin{array}{l}\text { Remission (DAS 28-CRP<2.6), n } \\
(\%)\end{array}$ & $12(33.3)$ & $20(58.8)$ & 0.032 \\
\hline
\end{tabular}

Conclusion: In our cohort subjects in remission had a lower prevalence of $\mathrm{CP}(\mathrm{OR}=0.3,0.1-0.9)$. No difference was found between cytokines regarding $\mathrm{CP}$. Subjects with active disease had a higher level of IL-1 than subjects in remission. To our best knowledge, this is the first study to evaluate levels of cytokines in Mexican RA-subjects.

\section{REFERENCES}

[1] López R, et al. Cardiovascular risk assessment in patients with rheumatoid arthritis. Autoimmun Rev 2016.

[2] Pasceri V, et al. A tale of two diseases: Atherosclerosis and rheumatoid arthritis Circulation 1999.

Disclosure of Interests: None declared

DOI: 10.1136/annrheumdis-2019-eular.4980

\section{SAT0081 BOTH OVERFAT AND MYOPENIA ARE ASSOCIATED WITH PHYSICAL DYSFUNCTION IN RHEUMATOID ARTHRITIS PATIENTS}

Chutao Chen, Jian-Zi Lin, Lijuan Yang, LI Qian-Hua, MA Jianda, Le-Feng Chen, Yingqian Mo, Lie Dai. Sun Yat-sen Memorial Hospital, Sun Yat-sen University, Department of Rheumatology, Guangzhou, China

Background: Comprehensive disease control has been recommended by EULAR guidelines for rheumatoid arthritis (RA) which includes simultaneous achievement of stringent control of the signs and symptoms of inflammation, the absence of radiographic progression and normal physical function. Identifying those patients at high risk of disability at a sufficiently early stage of their disease course presents a major challenge. The associations of body mass index (BMI) and body composition (BC) with physical activity function in RA patients still obscure.

Objectives: To investigate the characteristics of BC and BMI in RA patients and their association with physical activity function.

Methods: Consecutive RA patients were recruited and clinical data including disease activity, function and radiographic assessment were collected BC was assessed by bioelectric impedance analysis. Overfat was defined by body fat percentage (BF\%) as $\geq 25 \%$ for men and $\geq 35 \%$ for women. Myopenia was defined by appendicular skeletal muscle mass index (ASMI) $\leq 7.0 \mathrm{~kg} / \mathrm{m}^{2}$ in men and $\leq 5.7 \mathrm{~kg} / \mathrm{m}^{2}$ in women. Subjects were categorized by $\mathrm{BMI}$ as underweight $\left(\mathrm{BMl}<18.5 \mathrm{~kg} / \mathrm{m}^{2}\right)$, normal weight (18.5 $\left.\mathrm{kg} / \mathrm{m}^{2} \leq \mathrm{BMl}<24 \mathrm{~kg} / \mathrm{m}^{2}\right)$, overweight $\left(24 \mathrm{~kg} / \mathrm{m}^{2} \leq \mathrm{BMl}<28 \mathrm{~kg} / \mathrm{m}^{2}\right)$ and obese $\left(\mathrm{BMI} \geq 28 \mathrm{~kg} / \mathrm{m}^{2}\right)$ according to Chinese criteria. Physical dysfunction was defined by $\mathrm{HAQ}-\mathrm{DI} \geq 0.5$.

Results: There were 516 RA patients (mean age $49.8 \pm 12.9$ years old with $83 \%$ women) recruited, and $37 \%$ with physical dysfunction. Compared with those with normal physical function, RA patients with physical dysfunction 